\title{
Negócios de Impacto Socioambiental: desafios e estratégias para uma economia solidária
}

Social impact business: challenges and strategies for a solidary economy

\author{
Guillherme Abranches Sucupira \\ gassucupira@gmail.com \\ Graduando em Psicologia pela Pontifícia \\ Universidade Católica do Rio de Janeiro - \\ PUC-Rio.
}

\section{Ruth Espinola Soriano de Mello ruth@puc-rio.br}

Doutora em Ciências Sociais pela Pontifícia Universidade Católica do Rio de Janeiro PUC-Rio. Professora do Instituto de Administração e Gestão (IAG) da PUC-Rio.

\section{Resumo}

Esse estudo aponta que há diferentes formas de se empreender no campo social, uma delas é se posicionar como um negócio de impacto socioambiental, que têm estratégias e desafios específicos, ainda mais quando optam por assumir os princípios da economia solidária, deixando o campo teórico do empreendedorismo social ainda mais instigante para investigação de práticas sustentáveis que contribuem para contrapor o mainstream macroeconômico.

Palavras-chaves: Empreendedorismo social; Negócios de impacto socioambiental; Economia Solidária; Inovação social; Nova economia.

\begin{abstract}
This study points out that there are different ways of undertaking in the social field, one of which is to position itself as a business of socio-environmental impact which has specific strategies and challenges, even more when they choose to assume the principles of solidarity economy, leaving the theoretical field of even more exciting social entrepreneurship for investigating sustainable practices that contribute to oppose the macroeconomic mainstream. Keywords: Social entrepreneurship; Social impact businesses; Solidarity economy; Social innovation; New economy.
\end{abstract}




\section{Introdução}

No âmbito do sistema hegemônico econômico de capital, o que é possível fazer para que se tenha um mundo menos desigual e com menos pobreza? Essa pergunta está no cerne do campo do conhecimento do campo da Nova Economia em que fenômenos como a economia solidária, economia circular, criativa, regenerativa, compartilhada etc., assim como a dos negócios de impacto socioambiental positivo (NIS) se inserem ${ }^{1}$. O destaque aos dois modelos alternativos ao mainstream macroeconômico aqui proposto - economia solidária e os NIS - tem fundamentação na força dos princípios de solidariedade, cooperação e sustentabilidade.

A Nova Economia está intrinsecamente ligada ao surgimento das tecnologias da informação e da comunicação (TICs). Para as pessoas e as organizações "do século passado", esta questão é ainda mais presente, porque as novas gerações já nascem no contexto da convergência, comparativamente, aos que vivenciaram as dinâmicas entre o in e o off.

É neste contexto que foi criado o termo "Mundo Vuca", sigla do acrônimo do inglês para Volatility, Uncertainty, Complexity e Ambiguity (volatilidade, incerteza, complexidade e ambiguidade), configurando-se como estratégia comportamental de muitas organizações, a partir do início do século XXI (Wikipedia, 2019).

Para Gonçalves \& Ferro (2001), a economia teria mesmo deixado de ser algo possivelmente "modelizável", passando para um sistema de equilíbrio fechado. Segundo os autores, ela teria emergido como um sistema adaptativo complexo, aberto, evolutivo, até mesmo caótico, já que múltiplos e diferenciados agentes conviveriam de modo autogerido, a partir de interações dinâmicas. Já Hamel (2001) discorda da tese acima e aponta que existiriam duas realidades: uma realidade em que as organizações conseguem desenvolver tecnologias de um modo radical gerando salto operacional, abrindo novas oportunidades, redefinindo os benefícios aos seus usuários. E, uma outra que se vale da tecnologia como estratégia, em vez de ferramenta, não apresentando aprimoramento de valor entregado aos usuários. Para ele, o importante é se diferenciar de modo competitivo para garantir perenidade institucional. Entendemos que essa tese faz sentido, tanto para empresas, organizações sociais, quanto para o Estado.

\footnotetext{
1 Recomendamos ver também literatura circunscrita ao capitalismo consciente, economia donut, economia de Francisco e Clara, dentre outros arcabouços que viraram bandeiras de movimentos sociais de diferentes matizes.
} 
Assim, a economia solidária pode ser compreendida, no contexto atual, como um movimento plural, que envolve grupos de pessoas que além de questionar o desemprego, as condições de trabalho precárias e a concentração de renda, agem em prol da potência da economia solidária por meio de uma atividade econômica organizada de modo a servir ao seu maior objetivo, que é o desenvolvimento sustentável no âmbito pessoal e coletivo (Arruda, 2020).

Já os NIS têm no ato da criação de um negócio a sua essência. Foi a partir da resolução de um problema real em seu país - falta de crédito para as pessoas das castas mais baixas que o economista Muhammad Yunus (2010) foi criou o Grameen Bank e foi desenhando as bases para conformação de uma organização diferenciada mais adequada para resolver temáticas sociais, ambientais e econômicas, sob a égide de mecanismos de mercado. Assim, diante de experiências em Bangladesh, em um contexto de extrema pobreza, Yunus formulou seus princípios dos NIS em nível mundial os quais balizam hoje a atuação da Yunus Social Bussines Incubation, um programa internacional, que inclui o Brasil.

Os NIS vêm surgindo como uma nova tendência do empreendedorismo social na contemporaneidade. Para Yunus (2010), que opta por se referir aos NIS como negócios sociais (demarcando assim um diferencial importante no campo) são empreendimentos que necessariamente têm o impacto social como missão, sendo assim, uma das importantes formas de resolver problemas sociais e de melhorar a vida de muitas pessoas.

Assim como em qualquer tipo de empreendimento, a sobrevivência é um fator-chave, especialmente na fase inicial - momento startup ${ }^{2}$ - quando os riscos de descontinuidade são maiores (Sebrae, 2016). Nos negócios sociais, além desse desafio, existem algumas particularidades como, por exemplo, ser sustentável financeiramente e, ao mesmo tempo, gerar impacto social. A outra particularidade dos NIS refere-se aos critérios de mensuração do impacto os quais devem estar preferencialmente incorporados ao próprio modelo de negócios que não pode depender de receita de doações, filantropia e recursos de subvenção público ou privado (Mello, 2018). Diante desses complexos desafios e particularidades, algumas organizações foram criadas para apoiar os NIS.

$\mathrm{O}$ artigo pretende discutir os principais desafios e estratégias da realidade dos NIS no Brasil. Em suma, a questão que está em pauta é a seguinte: “Quais são os desafios e

\footnotetext{
${ }^{2}$ No Brasil, esta fase dura de 3 a 5 anos em média, a depender do setor econômico que a organização opera. Esse termo tem a ver com o momento em que a instituição nascente logra equacionar o investimento inicial aportado e obtém conhecimento mais maduro do segmento de mercado que atua (Mello, 2018).
} 
estratégias de operar um NIS e como podem lançar mãos dos princípios da economia solidária para qualificar sua atuação e seu propósito?”.

\section{Empreendedorismo}

O termo "empreendedor" se originou na França, por volta dos séculos XVII e XVIII, mas somente no século XIX é que o economista francês Jean Baptiste Say descreveu a ideia de empreendedor: "indivíduos aventureiros que estimularam o progresso econômico, encontrando novas e melhores maneiras de fazer as coisas" (Dees, 1998, p.4).

Em 1942, o economista austríaco Joseph A. Schumpeter acreditava que: "o empreendedor é o agente de processo de destruição criativa que é o impulso fundamental que aciona e mantém em marcha o motor capitalista" (Schumpeter apud Degen, 2009, p 1). É uma visão que enfatiza o papel do empreendedor de conseguir criar novos produtos e serviços para atender melhor às necessidades do mercado. Além disso, nos escritos de Joseph Schumpeter nos anos 1910 e 1920, o empreendedor é compreendido como sendo um inovador que impulsiona o desenvolvimento econômico através da reforma ou revolução do padrão de produção.

Peter Drucker, conhecido como "o pai da administração moderna” amplia a visão de Jean Baptiste Say dizendo que "nem todos os pequenos negócios novos são empreendedores ou representam um empreendimento" (Drucker, 1986, p.8). Para ele, as pessoas que abrem uma confeitaria ou mais um restaurante de comida mexicana no subúrbio americano estão assumindo um risco muito reduzido, assim, questiona se realmente elas têm o espírito empreendedor.

O estudo do empreendedorismo nos dias de hoje aborda com importância a questão do comportamento dos empreendedores. Durante a década de 1960, o objetivo do Programa das Nações Unidas para o Desenvolvimento (PNUD) era fortalecer as economias dos países em desenvolvimento e o caminho para alcançar esse objetivo era o fomento às pequenas empresas. Para fomentar o nascimento de pequenos negócios, foram implementadas três ações: o acesso ao crédito com juros atraentes; a melhoria da capacitação técnica dos candidatos; e a identificação de comportamentos e iniciativas presente nos empreendedores de sucesso (Grisi, 2008). 


\section{Empreendedorismo social}

O campo do empreendedorismo social tem sido estudado há décadas, trazendo correntes que apontam para um entendimento ligado a processo quando o governo ou organizações sem fins lucrativos operam usando princípios de negócios (Austin, Stevenson, \& Wei-Skillern, 2006; Mort, Weerawardena, \& Carnegie, 2002; Sharir \& Lerner, 2006), outros tratam como atividades de empreendedores convencionais que praticam ações de responsabilidade social corporativa (Baron, 2007; Young, 2001) ou como resultados de organizações filantrópicas (Reis \& Clohesy, 1999; Van Slyke \& Newman, 2006) ou de inovação social ${ }^{3}$ (Bornstein, 2004). Há ainda os que inserem o termo nas iniciativas economicamente sustentáveis que geram valor social (Emerson \& Twersky, 1996; Robinson, 2006; Dacin et al., 2010; Mello, 2018).

Os empreendedores sociais são conhecidos como "pragmáticos criativos" em prol das pessoas. Buscam atingir o objetivo social e conseguem enxergar oportunidades onde outros não veem nada. Outra característica do empreendedor social é considerar a população de baixa renda em seu mercado. Além das características citadas, os empreendedores sociais não trabalham dependendo do Estado ou de doações, sendo, assim, um modelo que preza pela autossuficiência econômica (Oliveira, 2004).

O empreendedorismo social se desenvolveu e hoje é considerado como uma grande tendência em muitos países, entre eles o Brasil. Na visão de Melo Neto e Froes (2002), o empreendedorismo social evidencia a busca dessa nova forma de se fazer negócios criando um novo paradigma. O objetivo não é mais o negócio pelo negócio em si, mas o negócio que tem na sociedade civil o seu principal foco de atuação, e a parceria envolvendo comunidade, governo e setor privado como estratégia (Melo e Froes, 2002).

Pode-se, portanto, afirmar que o conceito de empreendedorismo social tanto nacionalmente como internacionalmente está em construção. Em uma concepção mais ampla, Austin, Stevenson e Wei-Skillern (2006) afirmam que o empreendedorismo social se refere à uma atividade inovadora com um objetivo social podendo ocorrer no setor privado, no terceiro setor ou em organizações híbridas ${ }^{4}$. A partir dessa concepção, surgem novos termos para caracterizar iniciativas que operam na lógica de mercado, porém com objetivos de

\footnotetext{
${ }^{3}$ Temática esta cara à sociedade, ao campo dos NIS, do Terceiro Setor, das políticas públicas, da responsabilidade social empresarial, dentre outros.

${ }_{4}^{4}$ Para aprofundar o entendimento deste conceito indicamos Battilana \& Lee (2014) e Birkholz (2015). 
geração de valor social: NIS, negócios inclusivos, empresas sociais, dentre outras organizações.

Adicionalmente, conforme Mello (2018) quanto ao perfil de indivíduos que atuam como empreendedores sociais, importante resgatar que devem buscar equilibrar sua natureza inata de proverem brilho nos olhos (que reflete o perfil altruísta de indivíduos voltados a propósito/causa orientada ao impacto social positivo de suas ações) com atributos ligados a sangue no olhos (expressão associada à busca por crescentes indicadores financeiros, orientação comum aos empreendedores tradicionais). Mello fundamenta que "tão importante quanto colocar as organizações sociais em curso e de preservar sua orientação, é mantê-las ativas, longevas e sustentáveis desde o ponto de vista social, econômico e financeiro, independente se há ou não intenção de escalá-las" (2018, p.45). Esse aspecto é um dos desafios de aconselhamento dos mecanismos de apoio aos NIS nascentes para com seus empreendedores assistidos. Por fim, a revisão da literatura sobre a temática de negócios que geram impacto social e/ou ambiental positivo permite verificar que há algumas particularidades entre si, na sua estrutura organizacional e financeira, mas o que há de comum entre todos, seja alguns vendendo seus produtos e serviços à população de baixa renda ou outros promovendo oportunidades de trabalho e melhorias na qualidade de vida, é que são formas de gerar benefícios sociais e promover a maximização do impacto (Scherer, 2014).

\section{NIS}

O termo negócio social teria sido cunhado pelo economista e professor da Universidade Chittagong University, Muhammad Yunus. Yunus nasceu em Bangladesh e se envolveu com uma realidade de pobreza e fome muito séria em seu país, especificamente na comunidade de Jobra (Yunus, 2010). Diante disso, Yunus teve a ideia de fundar um banco para os pobres, o Grameen Bank, que se tornou uma organização híbrida cuja missão era resolver um problema social e não apenas maximizar lucros. O principal objetivo de Yunus era resolver o problema da falta de acesso aos serviços bancários das pessoas pobres que viviam na aldeia e em suas redondezas.

Na visão de Yunus, um negócio social tem como objetivo resolver um problema social utilizando métodos de negócios, inclusive criação e venda de produtos ou serviços. Considera-se como uma iniciativa economicamente rentável capaz de oferecer soluções para problemas sociais estruturados utilizando, para tanto, mecanismos de mercado. Assim, cada 
negócio social gera emprego, condições dignas de trabalho e, conscientemente, trata de desafios sociais específicos, tais como falta de educação, saúde e boa nutrição. Além da definição dos NIS de forma ampla, Yunus (2010) os classifica a partir de duas tipologias. O Tipo 1 é uma empresa com receitas e despesas equilibradas, sem perdas e sem dividendos, que se dedica a resolver um problema social e na qual seus proprietários são investidores que aplicam todos os lucros na expansão e melhoria do negócio. Já na do Tipo 2, a empresa visa lucro e é de propriedade de pessoa pobre. Nesse caso, como se trata de uma pessoa pobre, o lucro está retirando a pessoa da pobreza, portando caracteriza-se como um negócio social.

Além de Yunus, outros autores também contribuíram para este campo de estudo. O estadunidense e um dos grandes nomes do Marketing na Administração, Philip Kotler (2010), publicou no livro Marketing 3.0 sua visão sobre o que são os NIS:

um negócio social é desenvolvido com um propósito em mente desde seu nascimento. Mas também é possível transformar uma empresa estabelecida em um negócio social. O fator básico que determina se uma empresa é um negócio social será o fato de o objetivo social ser maior do que o objetivo de negócio e se refletir claramente em suas decisões. (Kotler, 2010, p.162, grifo nosso)

Além de Kotler, outros autores daquele país foram importantes para o desenvolvimento conceitual. Prahalad e Hart (2002), autores do livro A Riqueza na Base da Pirâmide, perceberam que as multinacionais negligenciavam um grande número de potenciais compradores classificados como base da pirâmide, por serem de baixa renda. Prahalad e Hart foram pioneiros em destacar a importância, de escala, que as multinacionais devem ter em mitigar os problemas sociais e ambientais.

Além da visão de negócios sociais nos países emergentes, apresentada por Yunus e outros como os autores supracitados, cabe destacar também a visão de alguns europeus. A motivação inicial que levou à criação das empresas sociais na Europa foi a oportunidade de oferecer serviços, que estavam na esfera do setor público, a custos mais baixos e geração de oportunidades de emprego para as populações desempregadas ou marginalizadas.

De acordo com a definição da rede de pesquisadores Emergence of Social Enterprise in Europe (EMES), as empresas sociais descrevem organizações que se baseiam na troca como sua principal fonte de renda e que consideram como negócios. Elas objetivam o lucro, mas também se definem como empresas que priorizam a participação dos beneficiários na tomada de decisão, bem como o reinvestimento dos lucros na própria organização, para ampliar o crescimento e o impacto (Young, 2009 apud Barki et al., 2013). 
Além disso, é importante ressaltar que esses negócios não fazem parte de um ecossistema homogêneo trazendo uma perspectiva diversa e complexa para o impacto social que cada um propõe. Portanto, definir, mensurar e principalmente, avaliar o impacto social proposto por iniciativa de mercado é uma tarefa complexa (Filho; Kiyama; Comini, 2013).

\section{Impacto nos NIS}

A Social Enterprise Knowledge Network (SEKN) propõe uma perspectiva ampla do entendimento sobre a inclusão econômica gerada pelos NIS ao definir valor social como "a busca de progresso social mediante a remoção de barreiras que dificultam a inclusão, a ajuda a aqueles temporariamente debilitados ou que carecem de voz própria e a mitigação de efeitos secundários indesejáveis da atividade econômica". Essa frase evidencia que mais do que entender as pessoas de baixa renda como consumidores ou produtores numa economia de mercado, essa perspectiva de valor social traz a visão do exercício da cidadania (Filho; Kiyama; Comini, 2013).

Para ilustrar a questão do impacto apresenta-se, segundo a Artemisia, as cinco principais dimensões de impacto social que os negócios podem gerar, tais como: diminuição dos custos de transação; redução das condições de vulnerabilidade; ampliação as possibilidades de aumento de renda; fortalecimento da cidadania; e os direitos individuais (Artemisia, 2020).

Com relação à primeira dimensão, o custo de transação pode ser definido como o custo em dinheiro e tempo gastos por um comprador no mercado. Dessa forma, pessoas pobres gastam mais dinheiro e recursos que os ricos para usufruir dos mesmos produtos e serviços. Isso ocorre em função da dificuldade de acesso devido às distâncias nos grandes centros e a falta de transportes públicos eficientes, pelas assimetrias de informação impostas por sua baixa escolaridade ou pela burocracia e custo do risco embutidos nos negócios direcionados a essa população.

Assim, como o acesso a bens e produtos, a dimensão de aumento de renda também é identificada mais facilmente na medida em que se propõem benefícios tangíveis para o usuário final e podem ser mensuradas com indicadores quantitativos. Apesar de parecer simples, o aumento de renda não deve ser entendido apenas como o aumento quantitativo de dinheiro, mas como a ampliação das possibilidades de escolha de um indivíduo de baixa renda (Artemisia, 2020). 
A redução das condições de vulnerabilidade refere-se à fragilidade que uma pessoa de baixa renda tem por ficar exposta a situações de risco, a condições de vulnerabilidade com mais facilidade e frequência, especialmente em situações de crise - perda de bens, doenças, falecimentos e gravidez não planejada (Artemisia, 2020), como as vivenciadas nos últimos anos no Brasil, em especial em 2020, com os efeitos avassaladores na sociedade advindos do isolamento sanitário social pela Covid-19.

Esse fato impede que as pessoas de baixa renda fortaleçam o exercício da sua cidadania podendo estar privadas de direitos individuais básicos de vida, liberdade e segurança, como o acesso à moradia digna e regularizada. Os NIS são importantes para diminuir tais assimetrias procurando interromper a ação dos intermediários, oferecer acesso ao mercado formal e disponibilizar informações relevantes para o exercício dos direitos individuais (Comini; Barki; Aguiar, 2013).

Pode-se notar que o conceito de NIS é interessante e inovador com um alto grau de complexidade. Na próxima seção serão abordados os desafios e as estratégias em relação aos NIS.

\section{Desafios e estratégias para empreender como NIS}

Nota-se que os problemas estão voltados à gestão da organização, a qualificação de um empreendedor social, bem como os desafios de mensurar o impacto social e a dificuldade de gerá-lo de uma maneira sustentável economicamente. Além disso, dois outros entraves observados têm a ver com a formação de parcerias e estruturação de um modelo de negócio de um NIS que extrapola a complexidade da operação dos negócios per se, abrangendo uma lógica de prover cadeias de valor coerentes e consistentes com seus propósitos existenciais.

Foram identificados em um estudo do Sebrae (2016) que os modelos e planos de negócio pouco ou mal desenvolvidos são sérios problemas. Segundo o mesmo estudo: “Os investidores apontam como um dos grandes desafios encontrar três elementos essenciais, e em sinergia, nos NIS: a identificação de uma oportunidade real de negócios relacionada a um problema social; um modelo de negócios robusto e uma forte equipe de gestão".

Além desses três pontos mencionados pelos investidores, um dos desafios dos empreendedores sociais é a capacidade de mensuração do valor social decorrente dos resultados de seus negócios. Uma das alternativas que tem sido adotada por empreendedores é a definição de indicadores como ferramenta para avaliar se os propósitos foram atingidos e 
para dimensionar as condições que possibilitem cumprir esta missão. Diferentemente de mensurar o valor econômico, basicamente o valor monetário criado pela atividade, a mensuração e análise do impacto social exigem a verificação da superação dos desafios propostos (Filho; Kiyama; Comini, 2013).

As questões que envolvem empreender como um NIS apontadas são relevantes e necessitam que o empreendedor seja capacitado e motivado para tais desafios. Por isso, a capacitação dos pequenos e novos empreendedores é fundamental para que seja possível uma gestão do negócio de qualidade. Segundo o Sebrae (2016), 23\% das micro e pequenas empresas do Brasil encerram suas atividades durante o primeiro ano de operação. Dessas, $67 \%$ das falências têm como principais causas a falta de capacitação, habilidade de gestão e de planejamento.

A falta de estruturação técnica do empreendimento, o conhecimento limitado sobre as fontes de financiamento, a falta de acesso a potenciais stakeholders, o baixo acesso à tecnologia de ponta e a dificuldade em monitorar e avaliar seus resultados econômicos e sociais de maneira clara e consistente são algumas das dificuldades enfrentas pelos empreendedores sociais no Brasil (Sebrae, 2016).

Alguns mecanismos de apoio aos NIS nascentes, como incubadoras, aceleradoras e agentes de apoio e fomento como o Sebrae, Artemisia, Endeavor e Aliança Empreendedora, têm atuado diretamente para solucionar esses problemas estimulando o mercado das micro e pequenas empresas. Muitas vezes o empreendedor, especialmente os da base da pirâmide, não possui recursos para pagar um serviço de assessoria e encontra dificuldade no primeiro momento de entender a importância desse apoio. É na criação de vínculo de confiança, do tempo e de resultados que os avanços dos negócios e das parcerias entre empreendedores e organizações de apoio se constroem (Neto; Valentini, 2013).

As principais estratégias dessas organizações em apoio aos NIS têm relação com oferta de mentorias, consultorias, formatação do modelo de negócios, capacitação dos empreendedores e articulação de investidores e parceiros (Sucupira, 2015).

A mentoria é um dos pontos-chave da estratégia de apoio e contribui para os desafios relacionados a vendas, produtos, modelo de negócios e escalabilidade. Além do aspecto técnico, o estado mental do empreendedor é fundamental para a realização do impacto e da sustentabilidade da organização. Daí a necessidade de trabalhar o indivíduo, a formação do empreendedor, de modo a contribuir ajudando o empreendedor a pensar qual o vínculo do NIS com a região onde ele está inserido e elaborar um diagnóstico considerando tal contexto. 
Por último, as parcerias são fundamentais, tais como, articulações locais e com grandes empresas, prefeituras, universidade e com centro de pesquisa. Quanto aos investidores, tornase essencial que haja uma "sensibilização" para que entendam melhor como funcionam os NIS e enxerguem o valor de modo mais amplo (Sucupira, 2015), de tal modo que implementem, por exemplo, uma lógica voltada ao que se tem apontado como sendo "capital paciente", diferenciado em relação a outras organizações tradicionais investidas.

\section{Considerações finais}

O fenômeno e a emergência dos NIS podem ser apontados como uma das respostas inovadoras e viáveis ao enfrentamento de problemáticas sociais e/ou ambientais estruturantes que acometem majoritariamente grande massa populacional de vulneráveis em nível mundial.

Pode-se observar que os desafios e as estratégias em relação aos NIS são de significativa relevância para uma nova forma de economia inspirada em princípios da economia solidária, especialmente da solidariedade e cooperação, na busca pelo equilíbrio com os ecossistemas e, finalmente, uma economia centrada no desenvolvimento das pessoas e da comunidade.

A qualificação dos empreendedores sociais e, portanto, a necessidade de capacitação, foi um dos desafios que se mostrou mais urgente nesse setor. Além disso, a elaboração de métricas de impacto social também é uma questão importante e recorrente no contexto dos NIS. Por fim, as principais estratégias das organizações que apoiam os NIS são principalmente pautadas nas mentorias e na capacitação dos empreendedores.

Essas questões-chave estão em consonância com que Yunus (2010) compreende como um negócio social de sucesso: boas práticas socioambientais, boa capacidade de construir equipes e boa capacidade de julgar os resultados de suas ações.

A expansão dos NIS como paradigma emergente também responde pelo enfrentamento de críticas das instituições vigentes (não apenas do Terceiro Setor, assim como do setor empresarial stritu sensu e governamental), de cidadãos cientes de seu papel de produção, reprodução e distribuição de boas formas de se conviver, consumir.

A singularidade dos propósitos dos NIS justifica sua relevância em busca de perenidade financeira autônoma, inclusive para garantir crescimento institucional e incremento da própria escala de sua atuação. Tal particularidade merece atenção de outros agentes econômicos e de novos estudos de diferentes perspectivas investigativas. 


\section{Referências bibliográficas}

ARRUDA, M. A visão biocêntrica da economia: aprendendo da economia de Francisco e Clara. Texto elaborado para o Programa de formação multiplicadora e continuada do FMCJS. Guapimirim, maio de 2020.

AUSTIN, J.; STEVENSON, H.; WEI-SKILLERN, J. Social and commercial entrepreneurship: same, different, or both? Entrepreneurship Theory and Practice, v.30, n.1, p.1-22, 2006.

BARON, D. P. Corporate social responsibility and social entrepreneurship. Journal of Economics and Management Strategy, v. 16, n. 3, p. 683-717, outono/2007.

BATTILANA, J.; LEE, M. Advancing research on hybrid organizing-Insights from the study of social enterprises. The Academy of Management Annals, 8(1), 2014. p.397-441.

BIRKHOLZ, C. Five Making hybrids work: aligning business models and organizational design for social enterprises. Dissertation of the University of St. Gallen, School of Management, Economics, Law, Social Sciences and International Affairs to obtain the title of Doctor of Philosophy in Management, Saint Gallen, May 19, 2015.

BORNSTEIN, D. How to change the world: Social entrepreneurs and the power of new ideas. New York: Oxford University Press. 2004.

COMINI, G. M.; BARKI, E.; AGUIAR, L. O novo campo dos negócios com impacto social. In: Negócios com impacto social no Brasil. Negócios com impacto social no Brasil. São Paulo: Editora Peirópolis, 2013, p.42-64.

DACIN, P. A.; DACIN, M.; MATEAR. M. Do we need a theory of social entrepreneuriship? Acad. Management Perspect. 24(3) 37-57. 2010.

DEES. J. Gregory, Social Entrepreneurship: Towards an entrepreneurial culture for social and economic development. Graduate School of Business, Stanford University, 1998.

DEGEN, J. R. O Empreendedor: empreender como opção de carreira. São Paulo: Pearson Prentice Hall, 2009.

DORNELAS, J. Empreendedorismo para visionários: desenvolvendo negócios inovadores para um mundo em transformação. Rio de Janeiro: Empreende / LTC, 2014.

DRUCKER, P. F. Inovação e espírito empreendedor. São Paulo: Pioneira, 1986.

EMERSON, J.; TWERSKY, F. New Social Entrepreneurs: The Success, Challenge, and Lessons of Non-Profit Enterprise Creation. The Roberts Foundation, San Francisco. 1996

FILHO, O, G.; KIYAMA, R. S.; COMINI, G. Os desafios de mensurar impacto social. In: BARKI, E; IZZO, D.; TORRES, H.; AGUIAR, L. (org.). Negócios com impacto social no Brasil. São Paulo: Peirópolis, v. 1, p. 211-226, 2013. 
GRISI, F. C. Empreendedorismo Social: uma pesquisa exploratória de ações de disseminação no Brasil. Porto Alegre: Departamento de Administração - PUC-RS, 2008. $148 \mathrm{p}$.

GONÇALVES, F.; FERRO, P. Estratégias empresariais e complexidade. In: Empresas, caos e complexidade; M. P. Cunha, J. M. Fonseca, \& F. Gonçalves (Ed.) Gerindo à beira de um ataque de nervos. Lisboa: 2001. p.142-155.

HAMEL, G. Não houve nenhuma revolução na web. [S.I.:S.n.], 2001.

KOTLER, P. Marketing 3.0 As forças que estão definindo o novo marketing. Rio de Janeiro: Elsevier, 2010.

MELLO, R. E. S. Incubadoras universitárias de negócios de impacto social: origens, diferenças e desafios. Tese de Doutorado. Rio de Janeiro - Departamento de Ciências Sociais: PUC-Rio, 2018. 384p.

MELO NETO, P. F.; FROES, C. Empreendedorismo social: a transição para a sociedade sustentável. Rio de Janeiro: Qualitymark, 2002.

MORT, G.; WEERAWARDENA, J.; CARNEGIE, K. Social entrepreneurship: Towards conceptualization and measurement. American Marketing Association Conference Proceedings, 13, 2002. p. 5.

NETO, M. A. E. de; VALENTINI, N. Empreendedores de Negócios com Impacto Social. In: BARKI, E.; IZZO, D.; TORRES, H. da G. Negócios com impacto social no Brasil. São Paulo: Editora Petrópolis Ltda., 2013.

OLIVEIRA, E. M. Empreendedorismo social no Brasil: fundamentos e estratégias. Tese de Doutorado. Franca: Unesp, 2004.

PRAHALAD, C. K.; HART, S. The Fortune at the bottom of the pyramid. Strategy + Business, Sheffield, v.1, n.26, 2002.

REIS, T.; CLOHESY, S. Unleashing new resources and entrepreneurship for the common good: A scan, synthesis and scenario for action. Battle Creek, MI: W. K. Kellogg Foundation. 1999.

ROBINSON, J. Navigating social and institutional barriers to markets: How social entrepreneurs identify and evaluate opportunities. In J. Mair, J. Robinson, \& K. Hockerts (Eds.), Social entrepreneurship. Basingstoke, UK: Palgrave Macmillan. 2006.

SCHERER, P. C. Entendendo os negócios com impacto social: uma análise dos elementos constituintes do modelo de negócio. Dissertação de Mestrado. Porto Alegre: Faculdade de Administração - PUC-RS, 2014. 114p.

SEBRAE - SERVIÇO BRASILEIRO DE APOIO ÀS MICRO E PEQUENAS EMPRESAS. Sobrevivência das empresas no Brasil. [S.I.] Sebrae, 2016. 
SHARIR, M.; LERNER, M. Gauging the success of social ventures initiated by individual social entrepreneurs. Journal of world business, v. 41, n. 1, p. 6-20, 2006.

STEVENSON, H.; WEI-SKILLER, J. Social and Commercial Entrepreneurship: Same, Different, or Both? Entrepreneurship Theory and Practice, 30, 1-22. 2006. doi:10.1111/j.1540-6520.2006.00107.x

SUCUPIRA, G. A. Desafios de Empreender Negócios Sociais no Brasil. Monografia. Rio de Janeiro: Departamento de Administração - PUC-Rio, 2015. 136 p.

SWOBODA, P. Schumpeter's Entrepreneur in Modern Economic Theory. Lectures on Schumpeterian Economics. New York: Springer-Verlag, 1983.

VAN SLYKE, D. M.; NEWMAN, H. K. Venture philanthropy and social entrepreneurship in community redevelopment. Nonprofit Management and Leadership, 16(3), 345-368. 2006. doi: $10.1002 / \mathrm{nml} .111$

YOUNG, D. Alternative perspectives on social enterprise. In: CORDES, J. 2009.

YOUNG, D. Organizational identity in nonprofit organizations: Strategic and structural implications. Nonprofit Management and Leadership, 12, 2001. p.139-57.

YUNUS, M. Criando um negócio social: como iniciativas economicamente viáveis podem solucionar os grandes problemas da sociedade. Rio de Janeiro: Elsevier, 2010.

\section{Consulta aos sites:}

ARTEMISIA. Disponível em: < http://artemisia.org.br/>._ Acesso em: 12 set 2020.

ASHOKA Empreendedorismo Social. Disponível em:

<http://www.ashoka.org.br/visao/empreendedorismosocial/>. Acesso em: 4 nov 2020.

WIKIPEDIA. Volatilidade, incerteza, complexidade e ambiguidade. Disponível em: <https://pt.wikipedia.org/wiki/Volatilidade,_incerteza,_complexidade_e_ambiguidade>. Acesso em: 5 out 2020. 